thống chăm sóc sức khỏe khi cần, người dân đồng ý tham gia và rất muốn tham gia chiếm tỷ lệ rất cao, lên đến $95,5 \%$, trong khi đó tỷ lệ hộ gia đình phân vân là $42,3 \%$. Kết quả này khá tương đồng với một nghiên cứu tại Đà Nẵng thực hiện trên bệnh nhẩn đái tháo đường khi chỉ ra có đển $52,4 \%$ người phân vân sử dụng khám chữa bệnh từ xa[8]. Một số yếu tố như tình trạng bệnh lý, đã từng nghe về Telemedicine, khả nẳng chi trả và lo ngại về tính an toàn, bảo mật của dịch vụ có thể ảnh hưởng đến việc sử dụng các dịch vụ chăm sóc sức khỏe từ xa $[3,8]$.

\section{KẾT LUẬN}

Kết quả nghiên cứu chỉ ra rằng tỷ lệ người dân sử dụng dịch vụ chăm sóc sức khỏe tại nhà có kết nối y tế từ xa chưa cao. Tuy nhiên phần lớn người dân và gia đình sẵn sàng tham gia loại hình dịch vụ chăm sóc sức khỏe này, tỷ lệ dao động giữa các dịch vụ khác nhau. Do đó, đây là bằng chứng rất quan trọng để có thể triển khai các mô hình chăm sóc sức khoẻ từ xa nhằm chăm sóc sức khỏe toàn diện cho người dân, đặc biệt trong bối cảnh đợt dịch COVID-19 lần thứ tư hiện nay ở Việt Nam đã và đang diễn ra hết sức phức tạp.

\section{TÀI LIẸU THAM KHẢO}

1. Song $X$, Liu $X$, Wang C (2020), "The role of telemedicine during the COVID-19 epidemic in China- experience from Shandong province". Critical Care; 24(1):1-4.

2. Võ Văn Thẳng, Võ Nũ̃ Hồng Đức ${ }_{\text {L }}$ Lương Thanh Bảo Yển, Vũ Thị Cúc, Nguyên Phúc
Thành Nhân (2021), "Đánh giá tình trạng và nhu cầu chăm sóc sức khoẻ của người cao tuổi tại tỉnh Thừa Thiên Huế". Tap chí Y học Việt Nam; 498(2): 35-39.

3. Nguyến Thi Lan Anh, Bùi Thi Ngoc Minh, Nguyễn Thị Thu Trang, Huỳnh Phước Tho, Nguyển Lân Hiếu, Đố Thị Thanh Toàn, Lưu Ngọc Hoạt (2021), "Nhu cầu và khả năng chi trả của người dân cho dịch vụ chăm sóc sức khoẻ tại nhà theo mô hình Buurtzorg có kết nối y tế từ xa tại quận nam Từ Liêm, Hà Nội năm 2021". Tạp chí Y hoc Viêt Nam; 501(2): 199-204.

4. Đinh Bảo Trâm và CS (2020), "Nhu cầu sử dung dịch vụ chăm sóc tại nhà của bệnh nhân sau đốt quy tai thành phố Hiuê, Việt Nam". Tap chí Y Dược học; 10 (1): 19 - 24.

5. Malouff, T. D., TerKonda, S. P., Knight, D., Perlman, A. I., Munipalli, B., Dudenkov, D. V., ... \& Buskirk, S. J. (2021). Physician Satisfaction With Telemedicine During the COVID-19 Pandemic: The Mayo Clinic Florida Experience. Mayo Clinic Proceedings: Innovations, Quality \& Outcomes, 5(4), 771-782.

6. Miyawaki, A., Tabuchi, T., Ong, M. K., \& Tsugawa, Y. (2021). Age and Social Disparities in the Use of Telemedicine During the COVID-19 Pandemic in Japan: Cross-sectional Study. Journal of medical Internet research, 23(7), e27982.

7. Đố Thị Thanh Toàn, Lưu Ngọc Minh, Đinh Thái Sơn và cộng sự' (2018), "Nhu câu tham gia dịch vụ chăm sóc sức khỏe tại nhà của người dân tại một khu đô thị Hà Nội". Tạp chí Nghiên cứu y học; 113 (4), 148-157.

8. Quách Hứu Trung, Võ Thi Hồng Hướng (2021). Kiến thức và nhu cầu về sử dụng dịch vụ khám chữa bệnh tữ xa của bệnh nhẩn đái tháo đường tại thành phố Đà Nằng. Tạp chí Nội tiết và Đái tháo đường; (46): 239-246.

\title{
KẾT QUẢ ĐIỀU TRI UNG THƯ BIỂU MÔ ĐẠI TRÀNG Ở BỆNH NHÂN TRẺ TUỔI TẠI BỆNH VIỆN K GIAI ĐOẠN 2016-2020
}

\section{TÓM TẮT.}

Mục tiêu:Đánh giá kết quả điều trị ung thư biểu mô đại tràng ở bệnh nhân trẻ tuổi tại bệnh viện $K$. Đối tượng và phương pháp nghiển cứu: Nghiên cứu mô tả hồi cứu kết hợp tiến cứu trên bệnh nhân từ 30 tuổi trở xuống được chẩn đoán ung thư đại tràng và điều trị tại Bệnh viện $K$ từ tháng 1/2016 đến tháng 12/2020. Kết quả: Tỷ lệ bệnh nhân đáp ứng hoàn

\footnotetext{
${ }^{1}$ Trường Đại học Y Hà Nội

${ }^{2}$ Bênh viên $K$

Chịu trách nhiệm chính: Nguyễn Thị Mai

Email: nguyenmai95hmu@gmail.com

Ngày nhận bài: 23.8.2021

Ngày phản biện khoa học: 20.10.2021

Ngày duyệt bài: 2.11.2021
}

Nguyễn Thị Mai ${ }^{1}$, Vũ Hồng Thăng ${ }^{1,2}$

toàn, tái phát sau điều trị lần lượt là 65,3\% và 20,4\%. Tỷ lệ bệnh nhân tái phát liên quan có ý nghĩa với nồng độ CंEA trước điều trị. Tỷ lệ sống thêm toàn bộ 5 năm là $37 \%$ và trung vị thời gian sống thêm toàn bộ 5 năm là $28,1 \pm 8,26$ tháng. Tỵ lệ sống thêm toàn bộ 5 năm có sự khác biệt giứa các giai đoạn bệnh, sự khác biệt có ý nghĩa thổng kê. Kết luận:Tỷ lệ sống thêm 5 năm toàn bộ là 37\%, liên quan có ý nghĩa thống kê với tình trạng di căn hạch và giai đoạn bệnh.

Tí khóa: ung thư đại tràng, bệnh nhân trẻ tuổi, kết quả điều trị.

\section{SUMMARY \\ TREATMENT OUTCOMES OF COLON CANCER IN YOUNG PATIENTS AT $K$ HOSPITAL IN PERIOD 2016-2020}

Aims: To evaluatethe treatment outcomes of 
colon cancer in young patients at $\mathrm{K}$ hospital in period 2016-2020. Patients and methods:Retrospective study combined prospective study on the young patients who were 30 years or younger and diagnosed with colon cancer, treated at K hospital, in 2016-2020. Results:The rates of complete response andrecurrent diseasewere $65,3 \%$ and $20,4 \%$, respectively. The rate of recurrent disease was related to theCEA concentration. The rate of OS at 5 years was $37 \%$. The median5-year OSwas $28,1 \pm 8,26$ months. There was significant difference in 5-year OSamong stages of disease. Conclusion: The rates of complete response andrecurrent disease were 65,3 and $20,4 \%$ and related to the CEA concentration. The rates of5-year OSwas 37\%. The relationship between 5 -year OS and stagewas significant.

Keywords: colon cancer, young patients, treatment outcomes.

\section{I. ĐĂT VẤN ĐỀ}

Ung thư đai tràng là môt bênh hay găp ở các nước phát triển, và đang có xu hướng tăng lên ở các nước đang phát triển. Ung thư đại tràng là ung thư phổ biến thứ 3 ở nam, thứ 2 ở nữ [1]. Một nghiên cứu ở 20 quốc gia châu Âu cho thấy trong thập kỷ qua, tỷ lệ mắc ung thư đại tràng đã tăng gần $8 \%$ mỗi năm ở những người ở độ tuổi 20 và $5 \%$ đối với những người ở độ tuổi 30 [2]. Định nghĩa của tuổi trẻ thường dùng khi bàn về bệnh nhân mắc ung thư đại tràng hiện còn chưa thống nhất. Một vài nghiên cứu sử dụng điểm cắt tữ 30 tuổi hoặc 45 tuổi trở xuống. Theo nghiên cứu của Kam, $72 \%$ bệnh nhân khi phát hiện bệnh đều ở giai đoạn Dukes C, D [3]. Một số nghiên cứu đã chỉ ra ung thư đại tràng ở người trẻ tuổi tiên lượng kém hơn trong khi những nghiên cứu khác cho thấy không có sự khác biệt đáng kể về tỷ lệ sống thêm [4]. Ở Việt Nam chưa có nghiên cứu nào về ung thư đại tràng ở bệnh nhân từ 30 tuổi trở xuống. Vì vậy, chúng tôi thực hiện nghiên cứu này với mục tiểu: Đánh giá kết quả điều trị của ung thư biểu mô đại tràng ở bệnh nhân tré tuổi tại bệnh viện $K$.

\section{II. ĐỐI TƯợNG VÀ PHƯƠNG PHÁP NGHIÊN CỨU}

2.1. Đối tượng nghiên cứu. Bao gồm 73 bệnh nhân $\leq 30$ tuổiđược chẩn đoán ung thư đại tràngvà điều trị tại Bệnh viện $\mathrm{K}$ từ tháng 1/2016 đến tháng 12/2020 và được theo dõi đến tháng $8 / 2021$.

\section{Tiêu chuấn lứa chọn}

- Tuổi $\leq 30$ tuổi

- Bệnh nhân chẩn đoán xác định ung thư đại tràng dựa trên các dấu hiệu lâm sàng, cận lâm sàng và bắt buộc phải có mô bệnh học là ung thư đại tràng.

- Không mắc bệnh ung thư khác, không mắc bệnh mạn tính trầm trọng đe dọa tính mạng trong thời gian nghiên cứu.

- Có hồ sơ lưu trữ đầy đủ.

- Bệnh nhânkhông bỏ điều trị và đồng ý tham gia nghiên cứu.

- Theo dõi sau điều trị đến khi bệnh nhân tử vong hoặc hết thời hạn nghiên cứu.

\section{Tiêu chuân loại trừ}

- Không phù hợp các tiêu chuẩn trên.

- Tiền sử điều trị các bệnh ác tính khác trong vòng 5 năm tính từ thời điểm được chẩn đoán ung thư đại tràng.

- Bệnh nhân bỏ điều trị không phải vì lý do chuyên môn.

\subsection{Phương pháp nghiên cứu}

- Thiết kế nghiên cứu

Nghiên cứu mô tả hồi cứu kết hợp tiến cứu.

\section{- Phương pháp thu thập số liệu}

Thu thập thông tin bệnh nhân theo mẫu bệnh án nghiên cứu thống nhất dựa trên hồ sơ bệnh án.

\subsection{Nội dung nghiên cứu}

- Đặc điểm lâm sàng, cận lâm sàng trước điều tri

- Kết quả điêu trị

o Phương pháp điêu trị áp dụng

o Tình trạng hiện tại: còn sống hay tử vong

- Tái phát: không tái phát, tái phát tại chỗ, tại vùng, di căn xa, thời gian tái phát

○ Vị trí di căn (gan, phúc mạc, phổi, xương...)

○ Thời gian sống thêm không bệnh, thời gian sống thêm toàn bộ

\subsection{Xử lý số liệu}

- Số liệu được mã hóa và xử lý bằng phần mềm SPSS 20.0.

- Ước lượng thời gian sống thêm không bệnh và sống thêm toàn bộ được phân tích theo phương pháp ước lượng thời gian theo sự kiện của Kaplan-Meier và sử dụng kiểm định Log-rank để khảo sát mối quan hệ. Kết quả được xem là có ý nghĩa thống kê khi $p \leq 0,05$, với độ tin cậy 95\%.

\section{KẾT QUẢ NGHIÊN CỨU}

Bảng 1: Phân bố bệnh nhân đáp ứng, tái phát sau điêu trị triết căn

\begin{tabular}{|c|c|c|}
\hline & Số lượng & Tỷ lệ (\%) \\
\hline $\begin{array}{c}\text { Không tái phát, } \\
\text { tiển triển }\end{array}$ & 32 & 65,3 \\
\hline Tái phát & 10 & 20,4 \\
\hline \multicolumn{2}{|c|}{ Thời gian tái phát (tháng) } \\
\hline 6-12 tháng & 6 & 60 \\
\hline >12-24 tháng & 3 & 30 \\
\hline >24-30 tháng & 1 & 10 \\
\hline Trung bình ( $\left.X^{ \pm S D}\right)$ & \multicolumn{2}{|c|}{$12,2 \pm 2,15$} \\
\hline
\end{tabular}


Nhận xét: Trong 49 bệnh nhân được điêuu trị triệt căn có 32 bệnh nhânkhông tái phát, di căn, chiếm tỷ lệ $65,3 \%$ và có 10 bệnh nhân tái phát (chiếm 20,4\%) trong đó có 1 ca tái phát tại vùng (2\%) và 9 ca di căn xa $(18,4 \%)$.Thời gian tái phát trung bình là $12,2 \pm 2,15$ tháng.

Bảng 2: Tái phát theo nồng độ CEA

\begin{tabular}{|c|c|c|c|c|c|c|}
\hline \multirow{2}{*}{$\begin{array}{c}\text { Nồng độ CEA } \\
\text { (ng/ml) }\end{array}$} & \multicolumn{2}{|c|}{$\begin{array}{l}\text { Tái phát } \\
\end{array}$} & \multicolumn{2}{|c|}{ Không tái phát } & \multirow{2}{*}{ Tông } & \multirow{2}{*}{ Giá trị p } \\
\hline & Số lượng & Tỷ lệ \% & Số lượng & Tỷ lệ \% & & \\
\hline $\begin{array}{l}\geq 5 \\
5\end{array}$ & $\begin{array}{l}5 \\
5\end{array}$ & 62,5 & 3 & 37,5 & 8 & 0,012 \\
\hline
\end{tabular}

Nhân xét: Nhóm BN có CEA $\geq 5$ có tỳ lệ tái phát $(62,5 \%)$ cao hơn nhóm có CEA<5 (14,7\%). Sự khác biệt có ý nghĩa thống kê với $p=0,012$.

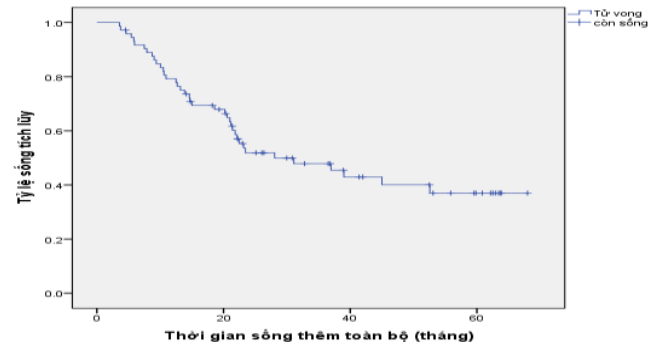

Biểu đồ 1: Thời gian sông thêm toàn bộ

Nhận xét: Tỷ lệ sống thêm 5 năm toàn bộ là $37 \%$, trung vị thời gian sống thêm toàn bộ là $28,1 \pm 8,26$ tháng.

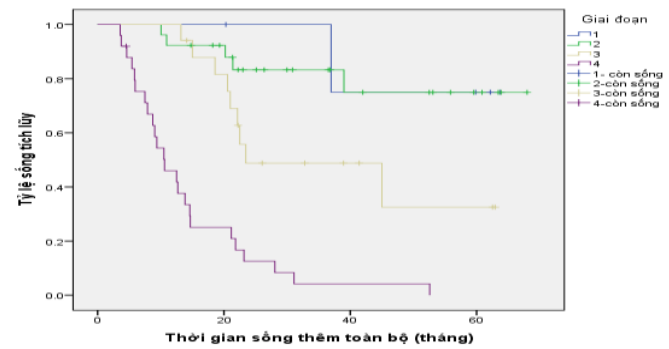

Biểu đồ 2: Thời gian sông thêm toàn bộ theo giai đoan bênh

Nhận xét: Giai đoạn càng muộn tỷ lệ sống thêm toàn bộ 5 năm càng ngẳn, sự khác biệt có ý nghĩa thống kê với $p=0,000$.

\section{BÀN LUẬN}

Kết quả điêu trị. Kết quả nghiên cứu của chúng tôi cho thấytrong 49 bệnh nhân được điều trị triệt căn có $65,3 \%$ bệnh nhân đáp ứng hoàn toàn và $20,4 \%$ tái phát. Đa số các trường hợp tái phát trong năm đâu sau điều trị. Thời gian tái phát trung bình là $12,2 \pm 2,15$ tháng. Kết quả nghiên cứu của chúng tôi phù hợp với nghiên cứu của Rodriguez và cộng sự với $65 \%$ bệnh nhân tái phát tại thời điểm 12 tháng [5].

Tỷ lệ tái phát theo nồng độ CEA. Nhóm CEA $\geq 5 \mathrm{ng} / \mathrm{ml}$ có tỷ lệ tái phát $(62,5 \%)$ cao hơn có ý nghĩa so với nhóm có CEA<5ng/ml $(14,7 \%)$. Kết quả nghiên cứu của chúng tôi phù hợp với các tác giả trong nước: Trần Vi Doanh năm 2004 tỷ lệ tái phát ở nhóm bệnh nhân có nồng độ CEA $\geq 10 \mathrm{ng} / \mathrm{ml}$ là $52,9 \%$ [6]. Như vậy, nồng độ CEA tăng cao trước điều trị là yếu tổ không thuận lợi ảnh hưởng kết quả điều trị của bệnh nhân trẻ tuổi mắc ung thư đại tràng.

Thời gian sống thêm toàn bộ. Biểu đồ 1 cho thấy tỷ lệ sống thêm 5 năm toàn bộ là $37 \%$, trung vị thời gian sống thêm toàn bộ là $28,1 \pm 8,26$ tháng. Kết quả nghiên cứu của chúng tôi thấp hơn so với Liying Zao năm 2017tỷ lệ sống thêm toàn bộ là $66,4 \%$ [7]. Có thể giải thích điều này vì bệnh nhântrong nghiên cứu của chúng tôi trẻ tuổi hơnnên tiên lượng xấu hơn.

Liên quan giữa thời gian sống thêm toàn bô và giai đoan bênh. Theo báo cáo của SEER năm 2018 tỷ lể sống thêm 5 năm toàn bộ giảm dần khi bệnh ở giai đoạn càng muộn: $90,6 \%$ với bệnh ở giai đoạn tại chỗ, $72,2 \%$ ở giai đoạn tại vùng và di căn là $14,7 \%$ [8]. Tỷ lệ sống thêm trong nghiên cứu của chúng tôi cũng giảm dần có ý nghĩa thống kê theo các giai đoạn. Tuy nhiên, tỷ lệ sống thêm 5 năm toàn bộ trong nghiên cứu của chúng tôi thấp hơnso với các báo cáo khác.

\section{KẾT LUÂN}

Tỷ lệ bềnh nhânđáp ứng hoàn toàn và tái phát sau điều trị trong nghiên cứu của chúng tôi lần lượt là $65,3 \%$ và $20,4 \%$. Thời gian tái phát trung bình là $12 \pm 2,15$ tháng. Tỷ lệ tái phát liên quan có ý nghĩa với nồng độ CEA. Thời gian sống thêm trung vị là $28,1 \pm 8,26$ tháng, tỷ lệ sống thêm 5 năm toàn bộ là $37 \%$, và liên quan có ý nghĩa thống kê với giai đoạn bệnh.

\section{TÀI LIÊU THAM KHẢO}

1. F. Bray, J. Ferlay, I. Soerjomataram và cộng sư (2018). Global cancer statistics 2018: GLOBOCAN estimates of incidence and mortality worldwide for 36 cancers in 185 countries. CA Cancer J Clin, 68(6), 394-424.

2. O'Connell J'B, Maggard MA, Livingston, et all. (2004). Colorectal cancer in the young. Am J Surg 187: 343-348.

3. Kam MH, Eu KW, Barben CP, Seow-Choen F. Colorectal cancer in the young: a 12-year review of patients 30 years or less. Colorectal Dis. 2004;6(3):191-194. doi:10.1111/j.1463- 
1318.2004.00596.x

4. Parramore JB, Wei JP, Yeh KA. Colorectal cancer in patients under forty: presentation and outcome. Am Surg 1998; 64: 563-8.

5. Rodriguez-Bigas MA, Mahoney MC, Weber TK, Petrelli NJ. Colorectal cancer in patients aged 30 years or younger. Surg Oncol. 1996;5(4):189194. doi:10.1016/S0960-7404(96)80043-0

6. Trân Vi Doanh (2005). "Nghiên cứu một số yếu tố nguy cơ di căn xa của ung thư đại trực tràng tại bệnh viện K Hà Nội từ 2003 đến 2004", Luận văn Thạc sỹ y học, trường Đại học $Y$ Hà Nội.

7. Zhao L, Bao F, Yan J, et al. Poor prognosis of young patients with colorectal cancer: a retrospective study. Int J Colorectal Dis. 2017;32(8):1147-1156. doi:10.1007/s00384-017-280

8. Cancer of the Colon and Rectum - Cancer Stat Facts. SEER. Accessed September 28, 2021. https://seer.cancer.gov/statfacts/html/colorect.htm

\section{ĐÁNH GIÁ TÌNH TRẬ CẢI THIỆN TRIẸU CHỨNG Ở BÊNNH NHÂN MẤT HOÀN TOÀN NHU ĐộNG THỰC QUẢN ĐIỀU TRI BẰNG THUỐC ỨC CHẾ BO'M PROTON KẾT HỢP PROKINETIC}

\section{TÓM TẮT}

Nghiên cứu theo dõi dọc được tiến hành nhằm đánh giá tình trang cải thiện triệu chứng sau 1 tháng điều trị bằng thuốc ức chế bơm proton (PPI) có/không kết hợp với prokinetic trên bênh nhân được chẩn đoán mất hoàn toàn nhu động thực quản bằng đo áp lực và nhu động thực quản độ phẩn giải cao (HRM). Kết quả có 50 bệnh nhân thu tuyển từ 9/2020 đến 6/2021 tại phòng khám đa khoa Hoàng Long, trong đó 12 bệnh nhân được điêu trị đợn thuần PPI, 38 bệnh nhân điêu trị kết hợp. Nhóm nghiên cứu gồm $58 \%$ nữ, tuổi trung bình là 48,4 $\pm 17,7$ năm, Điểm GERDQ trung bình của 2 nhóm trước điều trị lần lượt là $5,83 \pm 2,79$ và 6,68 $\pm 2,42$, điểm FSSG trung bình của 2 nhóm trước điều trị lần lượt là $10,17 \pm 5,34$ và 9,55 $\pm 5,08$, không có sư khác biêt giữa 2 nhóm. Sau 1 tháng điều tri, có sư cải thiện rõ rệt về điểm triệu chứng theo GERDQ, FSSG ở cả 2 nhóm. Tư khóa: mất hoàn toàn nhu động thực quản, đo áp lực và nhu động thực quản, thuốc ức chế bớm proton, prokinetic.

\section{SUMMARY}

\section{EVALUATING SYMPTOM IMPROVEMENT IN} PATIENTS WITH ABSENT CONTRACTILITY USING PROTON PUMP INHIBITORS COMBINED WITH PROKINETICS

A longitudinal study was conducted to compare the symptom improvement of patients diagnosed with absent contractility on high-resolution manometry after 1 month using proton pump inhibitors (PPIs) with or without prokinetics. This study included 50 patients between 9/2020 and 6/2021 at Hoang Long Clinic, of which 12 patients received PPI alone, 38 patients received PPI combined withprokinetic treament. The

\footnotetext{
${ }^{1}$ Trường Đại học Y Hà Nội

${ }^{2}$ Viện Nghiên cứu và Đào tạo Tiêu hóa, Gan mật

Chịu trách nhiệm chính: Đào Việt Hằng

Email: hangdao.fsh@gmail.com

Ngày nhận bài: 23.8.2021

Ngày phản biện khoa học: 18.10.2021

Ngày duyệt bài: 27.10.2021
}

prevalence of female was $58 \%$ and the mean age was $48.4 \pm 17.7$ years. The mean baseline GerdQ score of 2 groups were $5.83 \pm 2.79$ and $6.68 \pm 2.42$, the mean baseline FSSG score of 2 groups were10.17 \pm 5.34 and $9.55 \pm 5.08$. There were no differences in GerdQ score and FSSG score before treatmeant between 2 groups. After treatment, there was a significant improvement in GerdQ, FSSG scores in both groups.

Keywords: absent contractility, high-resolution manometry, proton pump inhibitors, prokinetics.

\section{I. ĐẶT VẤN ĐỀ}

Rối loan nhu đông thực quản không phải là môt bênh lí hiếm găp của đường tiêu hóa. Tỉ lê rối loạn nhu động thực quản dao động từ 27 53\% ở các bệnh nhân có triệu chứng nuốt nghẹn và đau ngực không do bệnh lí tim mạch. ${ }^{5}$ Trong các dạng rối loạn nhu động thực quản tiên phát, mất hoàn toàn nhu động thực quản (MHTNĐTQ) chỉ chiếm một tỉ lệ nhỏ khoảng 4,5\%.2 Tại Việt Nam, theo nghiên cứu của tác giả Đào Việt Hằng trên các bệnh nhân có triệu chứng đường tiêu hoá trên, tỉ lệ MHTNĐTQ là 2,4\% ${ }^{1}$

Cơchế gây MHTNĐTQ được cho là do rối loạn thân kinh cơ tại thực quản, tuy nhiên nguyên nhân dẫn đến tình trạng này hiện chưa rõ ràng, thường gặp MHTNĐTQ trong các bệnh lí tự miễn hệ thống, bệnh trào ngược dạ dày - thực quản (BTNDDTQ), đái tháo đường và các bệnh nhân sau phẫu thuât hoăc xa trị vùng cổ ngực. ${ }^{6}$ Các bệnh nhân có rối loạn MHTNĐTQ không có triệu chứng lâm sàng đặc hiệu, chủ yếu biểu hiện là trào ngược. Do đó, không thể chẩn đoán được rối loan MHTNĐTQ đơn thuân dựa vào tiếp cẩn các triệu chứng lâm sàng, mà cânkết hợp với các phương pháp thăm dò chức năng, trong đó quan trọng nhất là đo áp lực và nhu động thực quản đố phân giải cao (high-resolution manometry HRM). 